\title{
Cell Selectivity of Arenicin-1 and Its Derivative with Two Disulfide Bonds
}

\author{
Ju-Un Lee, Ka Hyon Park, ${ }^{\dagger \neq}$ Jee-Young Lee, Jinkyoung Kim, Song Yub Shin, ${ }^{\dagger \neq}$ \\ Yoonkyung Park, ${ }^{*}$ Kyung-Soo Hahm, ${ }^{\dagger+}$ and Yangmee Kim ${ }^{*}$ \\ Department of Bioscience and Biotechnologv, and Bio Molecular Informatics Center. Konkuk Lniversity. Seoul I $43-701$. Korea \\ ${ }^{*}$ E-mail: mkimiákonkukack ${ }^{\prime}$ \\ -Department of Bio-Materials, Graduate School and Research Center for Proteineous Materials. \\ Chosu Chiversit, Guangiu 501-759, Korea

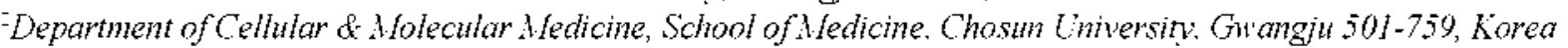 \\ $\$$ Department of Biotechnologvand BK21 Research Team for Protein Activit Control, Chosu Lniversin, Guangiu $501-759$. Korea \\ Received March 1. 2008
}

\begin{abstract}
Antibiotics has become more important in modem health care system. Antimicrobial peptide is one of the attractive candidates for new mechanism of antibiotics. Arenicin-1 (AR-1) is 21-residue antinucrobial peptide isolated from marine polychaeta. Arenicola marina with single disulfide bond forming an 18-residue ring [Orchinuikova. T. V. et al., FEBS Lett. 2004, 577. 209-214]. Our previous study on AR-1 and its linear derivative showed that disulfide bridge and the amphipathic â-sheet structure of the AR-1 play inportant roles in their biological activities. AR-1 has high antibacterial activity but it also displays hemolytic activity against human red blood cells. In order to develop more potent and more bacterial cell selective peptide, we designed and synthesized a new derivative, AR-1-C (RWCVYAYCRVRGVLCRYRRCW) by substitution of Val ${ }^{8.15}$ with $\mathrm{Cys}^{8.15}$. AR-1-C has higher antibacterial activity but displayed less hemolytic activity against human red blood cells than the parent AR-1. AR-1 has a two-stranded antiparallel â-sheet structures formung a large and flexible ring while $A R-1-C$ with two disulfide bonds forming a 12-residue ring has higher structural rigidity and higher hydrophobic-hydrophilic balance than AR-1. Peptide rigidity and optimum balance between the hydrophobic and hydrophilic phase in amphipathic à-sheet structure are important in biological activities of arenicin and its derivative
\end{abstract}

Key Words : Arenicin-1. Antimicrobial peptide. Disulfide bond. Stnucture-activity relationship

\section{Introduction}

Antibiotic agents have become essential in the modern health care system, assisting and complementing the natural inmume system. However. the appearance of resistant strains and the cytotoxicity of antibiotic agents have necessitated ongoing efforts to identify more potent and safer antibiotic agents. ${ }^{1-3}$ In this respect, the endogenous antinicrobial peptides and their derivatives are attractive candidates. Antimicrobial peptides play inportant roles in the innate host defense mechanisnts of most living organisms, including plants, insects. amphibians. and mammals. ${ }^{4 \cdot 7}$

A 21-residue antimicrobial peptide. Arenicin-1 (AR-1: RWCVYAYVRVRGVLVRYRRCW), a novel 21-residue antimicrobial peptide. was purified from coelomocytes of the marine polychaeta Arenicola manina (lugworm). ${ }^{s}$ This antimicrobial peptide contains a single disulfide bridge between $\mathrm{Cys}^{3}$ and $\mathrm{Cys}^{30}$, forming a large 18-residue ring. To deternine the role of this disulfide bond, we synthesized AR-1 (RWCVYAYVRVRGVLVRYRRCW) and its linear derivative. arenicin-1-S (AR-1-S: RWSVYAYVRVRGVLVRYRRSW). Activity assays revealed that AR-l-S is somewhat less active against bacterial cells than AR-I. Both peptides were very hydrophobic and displayed cy totoxicity against human red blood cells. Analysis of the tertiary structures of AR-1 and AR-1-S by NMR spectroscopy disclosed that AR-l has two-stranded antiparallel $\beta$-sheet structures with amphipathicity. while AR-1-S displays a random coil structure in DMSO.

In order to design more effective antimicrobial peptide without hemolytic activity. we synthesized a derivative, AR1-C (RWCVYAYCRVRGCLVRYRRCW) by substitution of valines with cystemes in the middle of $\beta$-sheet structure of AR-I (Table 1). We measured their antimicrobial activities against bacteria and hemolytic activities against human erytlurocy tes as well as leakage ability from liposomes composed of a mixture of phosphatidycholine (PC) and cholesterol $(\mathrm{CH})$. which mimics the manmalian cytoplasmic membranes. We proposed the structure-activity relationslip of AR-1-C based on its activities and the structure of AR-1.

\section{Methods}

Pepticle synthesis. Peptides were prepared by the standard Fmoc-based solid-phase method. ${ }^{11}$ Fmoc(9-fluoreny lmethoxycarbonyl)-Trp-Wang-resin, Fnoc-amino acids and other reagents for the peptide synthesis were purchased from Calibiochem-Novabiochem (La Jolla. CA, USA). DCC (dicyclohexylcarbodimide) and $\mathrm{HOBt}$ ( $N$-hydroxybenzotriazole) were used as coupling reagent, and ten-fold excess Fmoc-amino acids were added during every coupling cycle. The side protection of Cys was as follows: Cys(Trt) (for AR- 
1 synthesis) and $\mathrm{Cys}^{3}, 1 \mathrm{Trt}$ ) and $\mathrm{Cys} \mathrm{s}^{\mathrm{z}}$ 15 (Acm) (for AR-1-C synthesis). AR-1 containing a single disulfide bond was deprotected with trifluoroacetic acid/triisopropylsilane/ water/phenol/ethanedithiol $(82.5: 5: 5: 5: 2.5 . \mathrm{v} / \mathrm{v})$ for $2 \mathrm{~h}$ at room temperature. The reduced peptide of AR-I was airoxidized in ammonium acetate solution $(0.1 \mathrm{M}$ ammonium acetate, $0.1 \mathrm{M} \mathrm{NaCl} .20 \mathrm{mM} \mathrm{Na}=\mathrm{HPO}_{4}$. I mM EDTA. pH 8.0 ) in the presence of reduced and oxidized glutathiones (1:100:10 molar ratio of peptide:GSH:GSSG) for $2 \mathrm{th}$ at room temperature. ${ }^{11}$ Oxidized crude peptide was then purified by high performance liquid chromatography (HPLC) on a preparative $(15 \mu \mathrm{m}, 20 \times 250 \mathrm{~mm}) \mathrm{C}_{18}$ Vydac columm using water-acetonitrile gradient $(0-80 \%)$ containing $0.05 \%$ TFA. AR-1-C containing two disulfide bonds was deprotected with trifluoroacetic acid/trisopropylsilane/water/phenol/ ethanedithiol $(82.5: 5: 5: 5: 2.5 \mathrm{v} / \mathrm{v})$. The partially protected AR-1-C $\left[\mathrm{Cys}^{8,15}(\mathrm{Acm})\right]$ was dissolved in acetic acid solution (acetic acidwater $=1: 19, \mathrm{v} / \mathrm{v}$ ) containing $25 \%$ DMSO. and stirred until oxidation (peptide concentration: $30 \mu \mathrm{M}$ ). The solution was then made up to $30 \%$ acetic acid and the Acm groups were removed simultaneously with Cys oxidation by dropwise addition of $5 \mathrm{eq}$ of iodine (freshly prepared $5 \mathrm{mM}$ solution in methanol). The reaction mixture was directly loaded onto a preparative $(15 \mu \mathrm{m}, 20 \times 250$ $\mathrm{mm}) \mathrm{C}_{1 \S}$ Vydac column using water-acetonitrile gradient $(0$ $80 \%$ ) containing $0.05 \%$ TFA. The identity of AR-I and AR1-C were confinmed by MALDI-TOF MS (matrix-assisted laser-desorption ionization-time-of-flight mass spectrometry) (Shimadzu. Japan) (Table 1).

MIC test. The antimicrobial activities of the peptides were examined in sterile 96-well plates in a final volume of $100 \mu \mathrm{L}$ and the procedures are as follows. Briefly. aliquots $\left(100 \mu \mathrm{L}\right.$ ) of a bacterial suspension at $2 \times 10^{6}$ colony-forming units $(\mathrm{CFU}) / \mathrm{mL}$ in $1 \%$ peptone were added to $100 \mu \mathrm{L}$ of peptide solution (serial 2-fold dilutions in $1 \%$ peptone). After incubation for $18-20 \mathrm{~h}$ at $37^{\circ} \mathrm{C}$. the inhibition of bacterial growth was determined by measuring the absorbance at $620 \mathrm{~nm}$ with a Micro plate auto reader EL 800 (BioTek Instruments). The minimal inhibitory concentration (MIC) was defined as the lowest concentration of the peptide requited to inhibit bacterial growth. Two types of Gramnegative bacteria (Escherichia coli [KCTC 1682] and Salmonella tophimurium [KCTC 1926]) and two types of Gram-positive bacteria (Staphlococcts aturtus [KCTC 1621] and Staphlococcus epidermidis [KCTC 1917]) were purchased from the Korean Collection for Type Cultures (KCTC) at the Korea Research Institute of Bioscience and Biotechnology.

Table 1. Amino acid sequences of AR-1 and AR-1-C

\begin{tabular}{|c|c|c|c|}
\hline \multirow{2}{*}{ Peptide } & \multirow{2}{*}{ Sequence } & \multicolumn{2}{|c|}{ Molecular mass (Da) } \\
\hline & & Calculated & Observed \\
\hline AR-1 & RWCVYAYVRVRGVLVRYRRCV & 2758.3 & 2758.8 \\
\hline AR-1-C & RWCVYAYCRVRGVLCRYRRCV & 2768.3 & 2765.5 \\
\hline
\end{tabular}

Hemolytic activity. Hemolytic activity of the peptides was tested against human red blood cells (h-RBC). Fresh h$\mathrm{RBC}$ s were washed three times with phosphate-buffered saline (PBS; $35 \mathrm{mM}$ phosphate buffer containing $150 \mathrm{mM}$ $\mathrm{NaCl}, \mathrm{pH} 7.4)$ by centrifugation for $10 \mathrm{~min}$ at $1,000 \times \mathrm{g}$ and resuspended in PBS. The peptide solutions were then added to $50 \mu \mathrm{L}$ of h-RBC in PBS to give a final volume of $100 \mu \mathrm{L}$ and a final erythrocyte concentration of $4 \%(v / v)$. The resulting suspension was incubated with agitation for $l \mathrm{~h}$ at $37^{\circ} \mathrm{C}$. The samples were centrifuged at $1,000 \times \mathrm{g}$ for $5 \mathrm{~mm}$. Release of hemoglobin was monitored by measuring the absorbance at $405 \mathrm{~mm}$ of the supernatant Controls for no hemolysis (blank) and 100\% hemolysis, respectively. The percent hemolysis was calculated using the following equation

Hemoly sis $(\%)=\left[\left(\mathrm{OD}_{401} \mathrm{~nm}\right.\right.$ sample $-\mathrm{OD}_{4(1 \mathrm{~nm}}$ zero lysis $) /$ $\left(\mathrm{OD}_{4(15 \mathrm{~nm}} 100 \%\right.$ ly sis $-\mathrm{OD}_{4105 \mathrm{~s} \text { om }}$ zero lysis $\left.)\right] \times 100$.

Dye leakage from lipid vesicles. Calcein-entrapped SUVs composed of $\mathrm{PC} / \mathrm{CH}(10: 1, w / w)$ were prepared by vortexing the dried lipid in dye buffer solution $(70 \mathrm{mM}$ calcein. 10 mM HEPES. $150 \mathrm{mM} \mathrm{NaCl}, 0.1 \mathrm{mM}$ EDTA, pH 7.4). The suspension was sonicated in water bath and extruded through polycarbonate filters (two stacked $100 \mathrm{~nm}$ pore size filters) by an Avanti Mini-Estruder (Avanti polar Lipids inc., Alabaster). Untrapped calcein was removed by gel filtration on a Sephadex G-50 column. Usually, lipid vesicles were diluted to approximately 10 -fold after passing through a Sephadex G-50 column. The eluted calcein-entrapped vesicles were further diluted to the desired final lipid concentration for the experiment. The leakage of calcein from the SUVs was monitored by measuring fluorescence intensity at an excitation wavelength of $490 \mathrm{~nm}$ and an emission wavelength of $520 \mathrm{~nm}$ using a spectrophotomer (Perkin-Elmer LS55). For determination of $100 \%$ dye-release, $10 \%$ Triton- $\mathrm{X}_{1}(\omega)$ in HEPES-buffer ( $20 \mu \mathrm{L}$ ) was added to dissolve the vesicles. The percentage of dye-leakage caused by the peptides was calculated as follows:

$$
\text { Dye-leakage }(\%)=100 \times\left(F-F_{0}\right) /\left(F_{t}-F_{0}\right)
$$

Where. $F$ is the fluorescence intensity achieved by the peptides, $F_{i j}$ and $F_{\mathrm{t}}$ are fluorescence intensities without the peptides and with Triton $X \cdot 100$. respectively.

CD analysis. CD experiments were performed using a J810 spectropolarimeter (Jasco. Tokyo. Japan) with a 1-mm path length cell. The CD spectra of the peptides at $100 \mu \mathrm{M}$ were recorded at $25^{\circ} \mathrm{C}$ in $0.1-1 \mathrm{~mm}$ intervals from 190 to 250 $\mathrm{nm}$. To investigate the conformational changes induced by membrane environments. 2.2,2-trifluoroethanol (TFE)/water solution and sodium dodecyl sulfate (SDS) micelles of defined composition were added to the peptides. ${ }^{\text {I2 }}$ For each spectrum, the data from 10 scans was averaged and smootled using J-810. CD data were expressed as the mean residue ellipticity $[\theta]$ in deg $\mathrm{cm}^{2} \cdot \mathrm{dmol}^{-1}$.

Structure modeling of AR-1-C. Since NMR spectra of AR-1-C suffered from the spectral overlapping caused by the peptide aggregation. the model of AR-1-C was built by 
appropriate residue replacements based on NMR structure of AR-1. Two Val residues $\left(\mathrm{Val}^{\mathrm{s}}\right.$ and $\left.\mathrm{Val}^{15}\right)$ were replaced with Cysteines which enabled to form an additional disulfide bond. Final structure of AR-I-C was obtained by energy minimization. Energy minimization was performed with constrained disulfide bond between $\mathrm{Cys} \mathrm{s}^{\mathrm{z}}-\mathrm{Cys} \mathrm{s}^{15}$. Conjugated gradient algorithn was used to calculate the model structure with the consistent valence force field. These processes were performed using the progran Insightll/Discover (Accelrys Inc.. San Diego. CA). ${ }^{1 \hat{j}_{1} / 4}$ Ln order to investigate the structural transition of the our hypothetical structure of AR-1-C molecular dynamics (MD) simulation was performed. In case of $\mathrm{MD}$ sinulation. AR-1-C was solvated in rectangular boxes with DMSO molecules. All configurations were energy minimized with the steepest descents method for 1000 steps, to remove bad van der Waals contacts. MD simulation was performed during $25 \mathrm{~ns}$ using CHARMM.

\section{Results and Discussion}

In order to discover more potent and safer antimicrobial peptide. we designed and synthesized AR-I-C by substitution of $\mathrm{Val}^{8.15}$ with $\mathrm{Cys}^{\mathrm{S}, 15}$ based on the structure of AR1 deternined in our previous study. AR-1 has two-stranded antiparallel $\beta$-sheet structures. Since AR-I contains a single disulfide bond between $\mathrm{Cys}^{3}$ and $\mathrm{Cys}^{30}$ forming a large 18residue ring. its structure is quite flexible. In order to provide a more rigid $\beta$-sheet structure to AR-I. we introduce one more disulfide bond in the middle of the $\beta$-sheet structures by substitution of $\mathrm{Val}^{\mathrm{S}}$ and $\mathrm{Val}^{15}$ resulting in a 12-resiude ring. Figure 1 shows that skeletal structure of AR-1 determined previously and it shows the position of $\mathrm{Val}^{8}$ and $\mathrm{Val}^{15}$
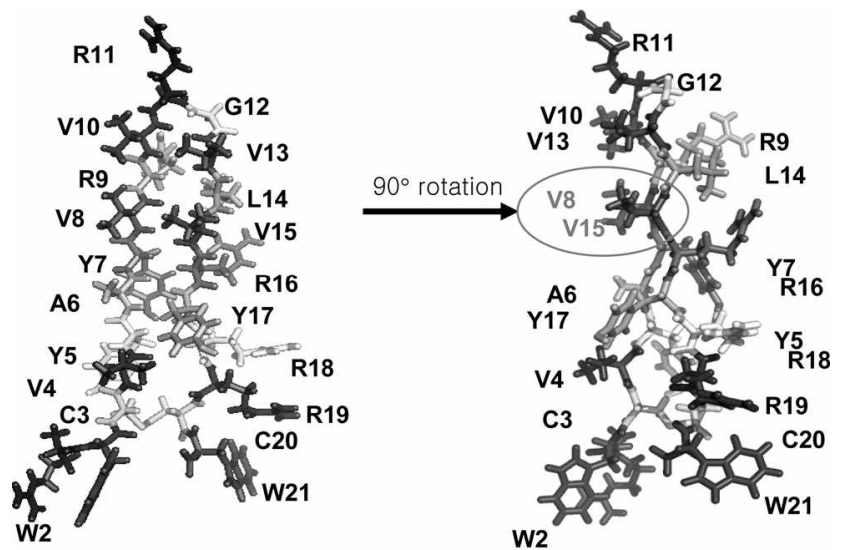

Figure 1. Skeletal structure of AR-1, which shows the position of $\mathrm{Val}^{8}$ and $\mathrm{Val}^{15}$ which were substituted with cysteines in AR-1-C. which protrude toward the same side and are suitable for additional disulfide bond.

The antimicrobial activities of the peptides were tested against two types of Gram-negative bacteria (Eschenichia coli and Salmonella typhimurim) and two types of Grampositive bacteria (Staphylococcus colreus and Siaphlococcus epidermidis). As listed in Table 2, both peptides displayed good antibacterial activities with MIC range of $2.0-8.0 \mu \mathrm{M}$. Generally. AR-1-C showed two fold higher antibacterial activities than AR-1. Then, we checked the hemolytic activity of the peptides against human red blood cell. As shown in Figure 2. AR-1-C displayed less hemolytic activity than AR1. Therefore, substitution of valines with cysteines reduced the hydrophobic potential and the length of $\beta$-sheet strand and resulted in decrease of hemolytic activity of AR-I-C compared to AR-1.

To examine cytotoxicity of the peptides, we measured their abilities to cause the leakage of fluorescent dye from $\mathrm{PC} / \mathrm{CH}(10: 1$. w/w) liposomes, which mimics manmalian cytoplasmic membranes (Figure 3). ${ }^{15.16}$ Melittin known as a strong peptide antibiotics with high hemolytic activity showed a strong dye leakage abilities. ${ }^{17}$ AR-1 was also very effective in inducing calcein leakage from $\mathrm{PC} / \mathrm{CH}(10: \mathrm{i}$. w/w) liposomes while AR-1-C showed very weak vesicle-disrupting activity compared to melittin and AR- 1 . This result implies that AR-1-C has higher bacterial cell selectivity than AR-1.

To investigate the secondary structures of AR-I-C in membrane-like enviromments, we measured CD spectra of AR-1-C dissolved in an aqueous solution, $1: 1$ (v/v) 2,2.2trifluoroethanol: $\mathrm{H}_{2} \mathrm{O}$ and $100 \mathrm{mM}$ SDS micelles. The CD spectra of AR-1-C in Figure 4 showed that AR- $-C$ has a

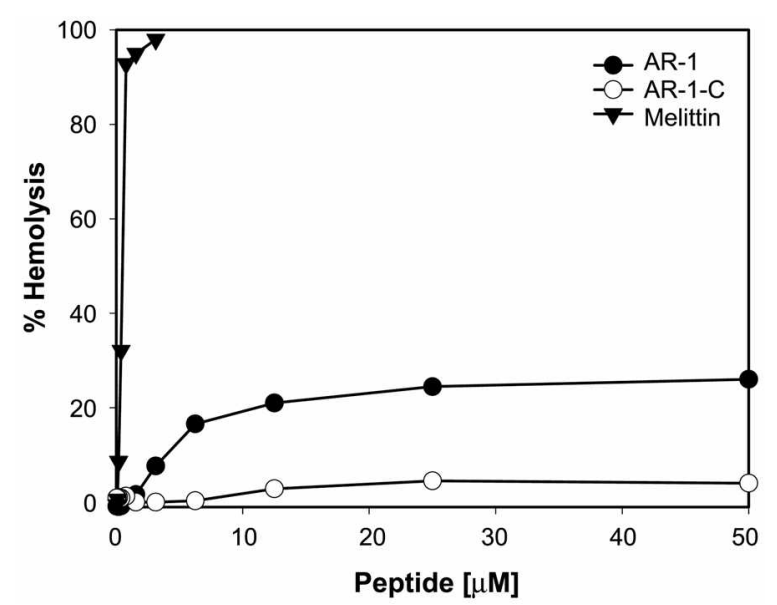

Figure 2. Dose-response curves of the hemolytic activity of the peptides against human red blood cells.

Table 2. Antimicrobial activities of AR-I and AR-I-C

\begin{tabular}{|c|c|c|c|c|}
\hline \multirow[b]{2}{*}{ Peptide } & \multicolumn{4}{|c|}{ Muimal inhibitory concentration $(\mu \mathrm{M})$} \\
\hline & $\begin{array}{c}\text { Escherichia coli } \\
\text { [KCTCl682] }\end{array}$ & $\begin{array}{c}\text { Salmonella tophimmrinm } \\
{[\mathrm{KCTC} 1926]}\end{array}$ & $\begin{array}{c}\text { Staphylococcus aureus } \\
\text { [KC'TC' 1621] }\end{array}$ & $\begin{array}{c}\text { Staphylococcus epidemidis } \\
\text { [KCTC 1917] }\end{array}$ \\
\hline AR-I & 4 & 4 & $4-8$ & $4-8$ \\
\hline AR-1-C & $2-4$ & 4 & $2-4$ & 4 \\
\hline
\end{tabular}




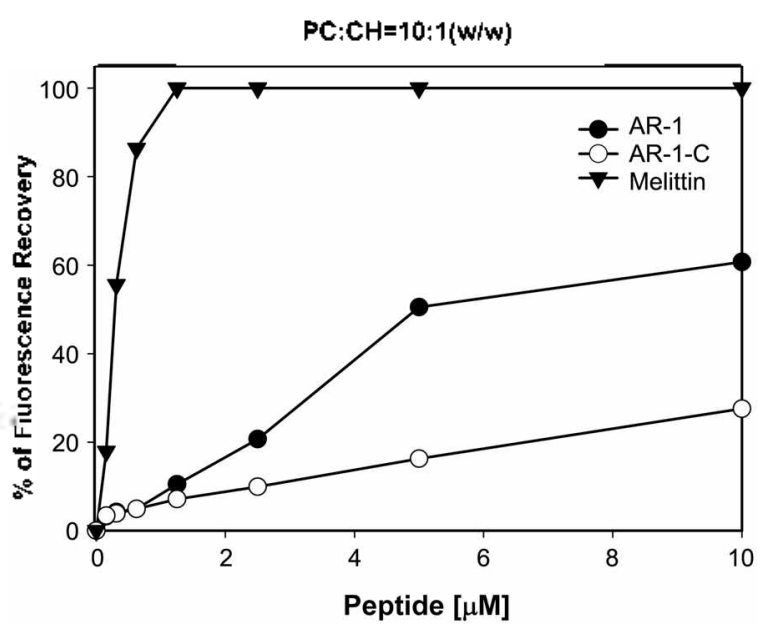

Figure 3. Leakage of the fluorescent dve, calcein from $\mathrm{PC} / \mathrm{CH}$ $(10: 1, w / w)$ SUV. The percentage of dye-leakage cansed by the peptides was measured.

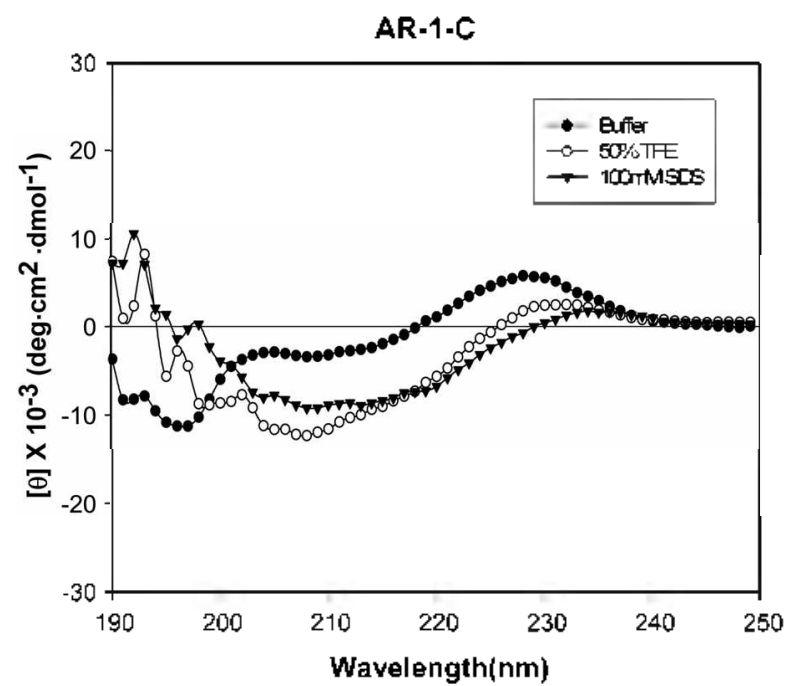

Figure 4. $C D$ spectra of $A R-1-C$ in membrane-mimetic environments.

random coil structures in aqueous solution while it has a minimum at $215 \mathrm{~nm}$ in SDS micelles which is a characteristics of $\beta$-sheet structure. ${ }^{18}$

Because of the peptide aggregation. NMR spectra of AR1-C' suffered from the peak overlapping and gave bad spectral resolutions. Therefore tertiary stnucture of AR-1-C was not able to be solved by NMR spectroscopy. Based on the structure of AR-1 determined by NMR spectroscopy previously ${ }^{9}$ we calculated a hypothetical structure of AR-1$C$ by energy minimization. In order to investigate the structural transition. MD simulation in DMSO box was performed. ${ }^{19}$ During $25 \mathrm{~ns}$ MD sinulation, there was no structural transition from our starting structure and no other local confomer was observed. Three dimensional structure of AR1 has more hydrophobic residues than hydrophilic residues resulting in high hemolytic activity. Since AR-1 has twostrand antiparallel $\beta$-sheet structure from $\mathrm{Ala}^{6}$ to $\mathrm{Ile}^{1 \mathrm{ij}}$ and $\mathrm{Val}^{13}$ to $\mathrm{TyI}^{17}$ with only one disulfide bond forming a flexible large ring, the structure is not rigid compared to other

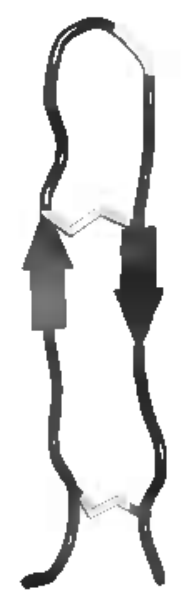

Figure 5. Structure of AR-I-C calculated based on the NMR structure of AR-1. Hydrophobic residues are colored red, whle hydrophilic residues are blue. Cysteme residues and disulfide bonds are colored yellow.

peptides with $\beta$-sheet structures including two or more disulfide bonds. ${ }^{\text {?il.2 }}$ Since AR-1-C had improved antimicrobial activities but showed much less hemolytic activity than AR-1. replacement of hydrophobic valine residues with cysteines decreased the hydrophobic potentials and cy totoxicity of AR-1-C compared to AR-1. As shown in hypothetical structure in Figure 5, addition of one more disulfide bond to AR-I may result in a shorter amplipathic $\beta$-sheet from $\mathrm{Cys}^{8}$ to $\mathrm{Ile}^{1 \mathrm{ii}}$ and $\mathrm{Cys}^{15}$ to $\mathrm{Tyr}^{17}$ forming a 12-residue ring with increased structural rigidity and balance between the hydrophobic and hydrophilic residues. Further study should be carried out to solve the peptide aggregation problems and to determine the accurate tertiary structure of AR$1-C$.

We can conclude that peptide rigidity and optimum balance between the hydrophobic and hydrophilic phase of amphipathic $\beta$-sheet structure are important in biological activities of AR-1 and AR-1-C. Structure-antibiotic activity relationships of AR-1 studied in this study should facilitate the design of novel non-cytotoxic peptide antibiotics with potent antibacterial activities.

Acknowledgments. This work was supported by the Research Program for New Drug Target Discovery (M10601000153-07N0100-15310) grant from the Ministry of Science \& Technology. South Korea. and by ERC grant from the Ministry of Science and Teclunology, Korea. through the Research Center for Proteineous Materials (R112000-083-00000-0). Ju-Un Lee and Jinkroung Kin are supported in part. by the second BK21 (MOE). This work was partly supported by a grant (Code 20080401-034-017) from BioGreen 21 Program. Rural Development Administration. Republic of Korea.

\section{References}

1. Lee. K. H: Lee, D. G.; Park, Y.: Kang. D. I.; Shin. S. Y: Hahm, K S.: Kim, Y. Biochem. J. 2006. 394. 105. 
2. Anthony, C.: Yanmin. H.: Richard. B.: Clive. P. Nature Reviews 2002.1.895.

3. Michael. Z. Nattre 2002. $115,389$.

4. Zasloff. M. Cum Opin. Immmol 1992, $4,3$.

5. Yount N. Y.: Baver A. S. Xiong. Y. Q: Yeman. M. R. Biopolymers (Peptide Science) 2006. 84, 435 .

6. Hancock. R. E. W. Diamond. G. Tends in Aficrobiolog' 1999. 8. 402.

7. Boman. H. G. J. Intern. Med. 2003. 25f. 197.

8. Orchimnikova. T. V.: Aleshina, G. M: Balandin. S. V: Krasnosdembskaya. A. D.: Markelov, M. L.: Frolova. E. I.: Leonova, Y. F: Tagaev. A. A.: Krasnodembsky, E. G.: Kolryakov, V. N. FEBS Leth. 2004. 577.209.

9. Lee. J. U.: Kang. D. I.: Zhu. W. L.: Shin. S. Y: Hahm. K. S.: Kim. Y. Biopolymers (Peptide Science) 2007. 88. 208.

10. Fields, G. B.: Noble. R. L. Int. J. Pept. Protem Res. 1990. 35. 161.

11. Vila-Perello, M.: Sanchez-Vallet, A.: Garcia-Olnedo, F; Molina, A.: Andreu. D. FEBS Lett. 2003. 536.215.

12. Kang. D. I.: Back. D.: Shin. S. Y.: Kim. Y. Bull. Konean Chem.
Soc. 2005.26 .1225$.

13. Lee. J. Y.: Baek. S.: Kim. Y. Bull. Komean Chent. Soc. 2007. 28. 379.

14. Lee. J. Y; Lee. S. A.; Kim. Y. Bull. Korean Chem. Soc 2007. 28. 941.

15. Shin, S. Y.: Kang. J. H.: Jang, S. Y.: Kim. Y.: Kim. K. L.: Hahm. K. S. Biochem Biophy deta 2000. $1+63.209$.

16. Zhu. W. L.: Lan1. H.: Park. Y: Yang. S. T.: Kimn. J. I.: Park. I. S.: You. H. J.: Lee. T. S.: Park. Y. S.: Kim. Y.: Hahm. K. S.: Shin. S. Y. Biochemisny 2006. 45, 130007.

17. Zhu. W. L: Nan, Y. H.: Hahm. K. S.; Shin, S. Y. Jownal of Biochemisny and Molecular Biology 2007. 10.1090.

18. Ahr1. H. S.: Cho. W.: Kang. S. H.: Ko. S. S.: Park. M. S.: Cho. H.: Lee. K. H. PEPTIDES 2006. 27. 640 .

19. Lee. S. H. Bull Korem Chem. Soc. 2006. 27. 1154.

20. Bulet. P.: Stocklin, R:; Menin. L. Inmmol. Rev 2004, 198. 169.

21. Laederach, A.; Andreotti, A. H.: Fulton. D. B. Biochemistry 2002. 4. 12359

22. Powers. I. S.: Rozek. A.: Hancock. R. E. Biochent Biophss. Acta 2004. 1698. 239. 